\title{
Study on Fire Extinguishing Performance of Superfine Powder Fire Extinguishing Agent in a Cup Burner
}

\author{
T. Chen, X.C. Fu, J.J. Xia, L.S. Jing, C. Hu \\ Tianjin Fire Research Institute \\ MPS \\ Tianjin 300381, China
}

\begin{abstract}
A modified cup-burner apparatus with a vibrating-spiral micro feeder was developed for testing the extinguishing performance of superfine powder fire extinguishing agent (SPEA). The suspension velocity of SPEA particles was calculated using the suspension-grade-model (SGD). The formation mechanism of SPEA-based aerosols was investigated theoretically, and the minimum air velocity for the SPEA particles was about $0.05 \mathrm{~m} / \mathrm{s}$. Experiments were conducted on both ethanol and heptane fuels burning flames using $\mathrm{NH}_{4} \mathrm{H}_{2} \mathrm{PO}_{4}$-based SPEA with air flow rate of $60 \mathrm{~L} / \mathrm{min}$. The results show that the minimum extinguishing concentrations (MEC) of $\mathrm{NH}_{4} \mathrm{H}_{2} \mathrm{PO}_{4}$-based SPEA for ethanol and heptane fuel are $79.8 \mathrm{~g} / \mathrm{m}^{3}$ and $98.8 \mathrm{~g} / \mathrm{m}^{3}$, respectively. It is demonstrated that the $\mathrm{NH}_{4} \mathrm{H}_{2} \mathrm{PO}_{4}$-based SPEA is a highly efficient fire-extinguishing agent, which is an average of 2 3 times more effective than $\mathrm{CF}_{3} \mathrm{Br}$, and an average of $5 \sim 8$ times more effective than HFC-227ea.. This research is helpful for the engineering design of superfine powder fire extinguishing equipment, as well as has vital significance to the fire protection.
\end{abstract}

Keywords-superfine powder fire extinguishing agent; extinguishing concentration; aerosol; cup-burner

\section{INTRODUCTION}

Superfine powder fire extinguishing agent (SFEA) with small size and large specific surface area can quickly spread and suspend in the air after being discharged, and then forms stable aerosols. Therefore, SFEA normally referred to as cold aerosol fire extinguishing agent ${ }^{[1-2]}$. Previous studies showed that SFEA has similar properties to gas fire extinguishing agent after being applied into the air. Superfine power fire extinguishing agent can bypass obstacles and suspend for some time when discharged by high pressure gas. Therefore, it can be used as a way of total flooding extinguishing in engineering application. Besides, SFEA can be used as the substitute of halon or hydrofluorocarbons (HFCs) fire extinguishing agent, such as Halon1301, HFC-227ea.and HFC-23, because it neither destroys the atmospheric ozone layer nor leads to global warming $^{[3] .}$ It will be widely employed in the future due to its low cost and cheap equipment. However, there are a lack of enough research on the performance and measurement of superfine powder total flooding as well as effective methods to evaluate the extinguishing performance of total flooding. Furtherly, the lack of key application parameters such as critical extinguishing concentration seriously limits the application of superfine power fire extinguishing technology.
Fire suppression model being closed to practical fire situation was used for assessing the extinguishing performance of superfine power fire extinguishing system. As described in GA 578-200<Superfine powder fire extinguishing agent $>$, fire extinguishing test was conducted in a $100 \mathrm{~m}^{3}$ space to evaluate performance of SFEA on standard fire. In every test, it will cost too much material, and it is difficult to determine critical fire extinguishing concentration. Fleming and Hmins ${ }^{[4-5]}$ compared and analyzed cup-burner, Convection diffusion flame model and turbulent spray flame burner through studying the performance of large number of gas extinguishing agents. Results indicated that the characteristic of cup-burner flame structure was more close to real fire and reflected the interaction between fire extinguishing agent and fire rather than other models. Hirst ${ }^{[6]}$ reported that fire in cup-burner was more difficult to being extinguished and required more $20 \%$ extinguishing concentration than fire in full size experiment test. Hirst thought that security coefficient had been considered essentially while extinguishing concentration was measured by cup-burner model. Many studies demonstrate that test methods based on cup-burner model is a scientific way to assess the total flooding performance of fire extinguishing agents, which has been accepted by the countries around the world and international organization for standardization.

Hamins $^{[7]}$ has measured the suppression effectiveness of $\mathrm{NaHCO}_{3}$ by modified cup-burner. Whereas, the feeding rate is unstable, the calibration of feeding rate is too complicate and the object of study is too single. And the effect of suspension characteristics and air velocity on extinguishing concentration is also not considered. Given this, firstly, a modified cup-burner apparatus with a vibrating-spiral micro feeder was developed in this paper. Secondly, the formation mechanism of aerosols was investigated by theoretical calculation and test. Finally, this paper determined the extinguishing concentrations of $\mathrm{NH}_{4} \mathrm{H}_{2} \mathrm{PO}_{4}$-based SPEA with different fuels. For comparison, experiments results using several common gaseous agents with the same test method were also reported.

\section{EXPERIMENT}

\section{A. Fire Extinguishing Agent}

As main material, $\mathrm{NH}_{4} \mathrm{H}_{2} \mathrm{PO}_{4}$ powder was milled by Fluidized bed air flow crushing method before silicone oil was used to the surface modification of the SFEA. The particle size 
distribution of $\mathrm{NH}_{4} \mathrm{H}_{2} \mathrm{PO}_{4}$-based SPEA was measured by laser particle size analyzer (Mastersizer 2000), as shown in Figure 1. The results showed that $\mathrm{D}_{50}$ and $\mathrm{D}_{90}$ for $\mathrm{NH}_{4} \mathrm{H}_{2} \mathrm{PO}_{4}$-based SPEA was $7.21 \mathrm{um}$ and $13.29 \mathrm{um}$, respectively.

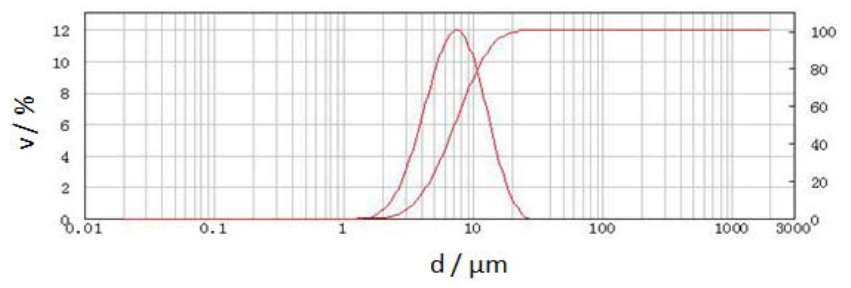

FIGURE I. PARTICLE SIZE DISTRIBUTION OF SPEA.

\section{B. Experimental Apparatus}

A modified cup-burner apparatus was developed for testing the extinguishing performance of SFEA with a vibrating-spiral micro feeder. As shown in Figure 2, circular cup was made of stainless steel with $25 \mathrm{~mm}$ internal diameter and $1-2 \mathrm{~mm}$ wall thickness.

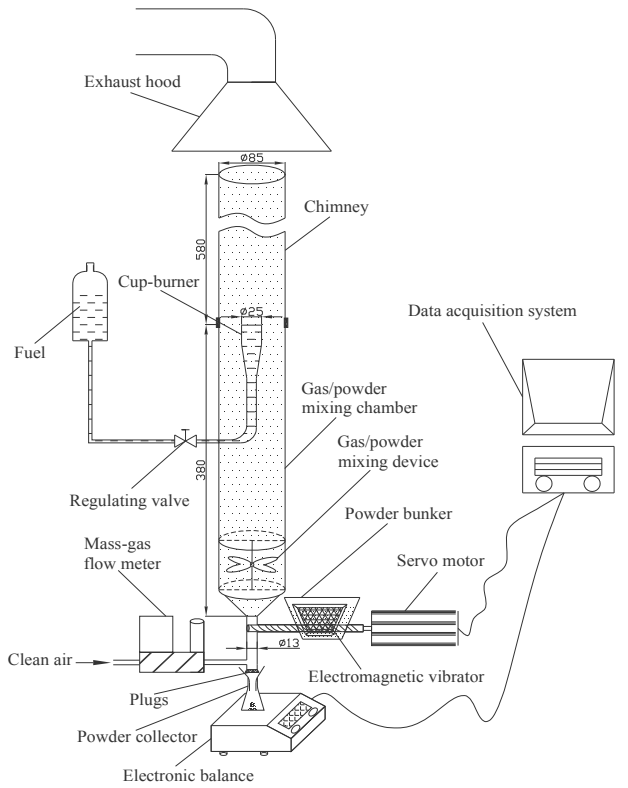

FIGURE II. SCHEMATIC DIAGRAM OF EXPERIMENTAL APPARATUS.

The chimney of burner with $85 \mathrm{~mm}$ internal diameter was cylindrical. The feeding rate of superfine powder, which was calibrated through powder collector and powder quality collector, was regulated by controlling electromagnetic vibrator switch and adjusting the speed of servo motor. Air provided by compressor was dried through filter and then injected into the bottom of burner, flow rate of which was altered by gas mass flow meter (MFC D07-9E). Under electromagnetic vibration, superfine powder was driven by screw and injected into the bottom of cup-burner. Thereafter, superfine powder was driven into mixing chamber together with air and formed uniform aerosols under vigorously stirring through mixing apparatus. The mixing apparatus carried with blades rotating automatically under the effect of the airflow.

\section{Experiment Procedure}

Before the experiment, the powder feeding rate was calibrated. Firstly, 150g superfine powder was added into the powder bunker and air was stopped injecting into cup-burner, followed by removing the plug below air inlet. Secondly, the electromagnetic vibrator and servo motor were opened and then superfine powder was provided after setting up the speed of servo motor. Finally, the mass of agent in powder collector was recorded once a second by powder quality collector.

During the experiment, the plug was set up below air inlet and air was injected into cup-burner. Meanwhile, fuel was lit and burnt for $10 \mathrm{~s}-30 \mathrm{~s}$. Then the electromagnetic vibrator and servo motor were opened after setting up the speed of servo motor. Superfine powder was driven into cup-burner with constant feeding rate and the time was recorded as agent contacted with fire. If the time exceeded $60 \mathrm{~s}$, while the fire still burned, the test continued after raising the speed of motor or decreasing airflow until the fire was put out. Parameters, such as attack time, motor speed and airflow, were recorded during this time. The powder delivery rate could be obtained from motor speed and extinguishing concentration was calculated by formula (1).

$$
C=\frac{q}{V_{\text {powder }}+V_{\text {air }}} \times 1000
$$

Where, $C$ stands for extinguishing concentrations of SFEA by mass, $\mathrm{g} / \mathrm{m}^{3} ; q$ stands for SFEA powder delivery rate by mass, $\mathrm{g} / \mathrm{s} ; V_{\text {air }}$ stands for Air volume flow, $\mathrm{m}^{3} / \mathrm{s} ; V_{\text {powder }}$ stands for Volume flow of SFEA powder, $\mathrm{m}^{3} / \mathrm{s}$.In view of the fact that the powder density is far greater than the air, So this value $\left(V_{\text {powder }}\right)$ can be ignored when the actual calculation.

\section{RESULTS AND DISCUSSION}

\section{A. Relationship between Powder Delivery Rate and Motor Speed}

In Figure 3, the mass of $\mathrm{NH}_{4} \mathrm{H}_{2} \mathrm{PO}_{4}$ was recorded as motor speed changed. The feeding rate as a function of motor speed was shown in Figure 4.

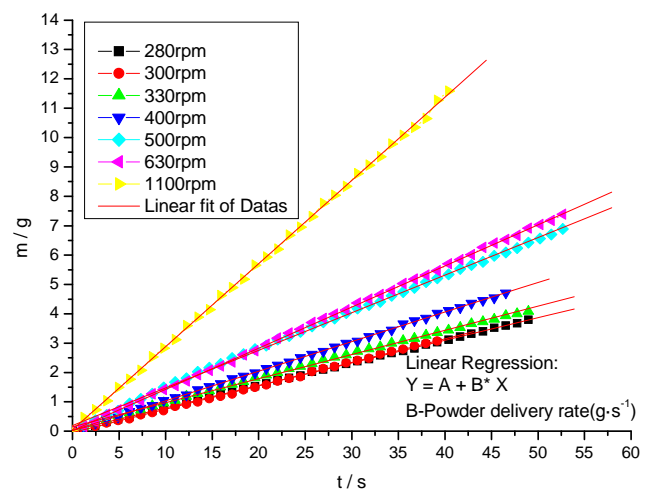

FIGURE III. CUMULATING MASS OF NH4H2PO4 POWDER CHANGING WITH TIME. 


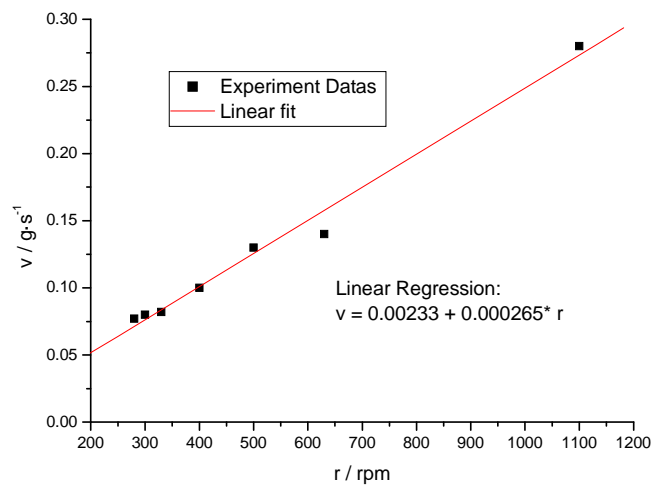

FIGURE IV. POWDER DELIVERY RATE AGAINST THE MOTOR SPEED.

Figure 3 indicates that the mass increases linearly with time at constant motor speed when Electromagnetic vibrator is open. Figure 4 shows that the feeding rate increases with motor speed and screw speed. According to different characteristics of superfine powder, feeding rate can be adjusted freely from $0.02 \mathrm{~g} / \mathrm{s}$ to $0.30 \mathrm{~g} / \mathrm{s}$ by changing motor speed. Therefore, modified apparatus with a vibrating-spiral micro feeder can supply continuous, stable and uniform powder which meets the requirement of fire extinguishing performance.

\section{B. Aerosol Formation and Its Relationship with the Air Flow}

In the system containing particle and airflow, airflow will move upward at certain speed. According to principle of gas-solid two phase fluid mechanics ${ }^{[8-9]}$, the particle will fall when the speed of airflow is lower than the particle free settling velocity. The particle will rise when the speed is higher than the particle free settling velocity. If the speed of particle and airflow is equal, particle will swing in a horizontal plane and the speed of airflow is known as the free suspension velocity of solid particles or simply suspension velocity for short. Apparently, suspension velocity and the particle free settling velocity are equal in value, but opposite in direction. Suspension velocity depends on its resistance characteristics such as density, volume and shape. Besides, the density and dynamic viscosity of air also affects suspension velocity.

To obtain aerosols in cup-burner, it must be ensure that superfine powder move upward, that is to say, the speed of airflow must higher than suspension velocity. In general, the suspension velocity of powder particle is calculated using the suspension-grade-model (SGD) according to principle of gas-solid two phase fluid mechanics. Applicable particle size range formula for viscous resistance area is shown in formula (2).

$$
d_{s} \leq 1.225\left[\frac{\mu^{2}}{\rho\left(\rho_{s}-\rho\right)}\right]^{\frac{1}{3}}
$$

Where, $d_{s}$ stands for SFEA particle diameter, $\mathrm{m}$; $\mu$ stands for dynamic viscosity of air, $\mathrm{Pa} \bullet \mathrm{s}$, which is $0.0000179 \mathrm{~Pa} \bullet \mathrm{s}$ under standard conditions; $\rho$ stands for air density, $\mathrm{kg} / \mathrm{m}^{3}$, which is $1.205 \mathrm{~kg} / \mathrm{m}^{3}$ under standard conditions; $\rho_{s}$ stands for powder density, $\mathrm{kg} / \mathrm{m}^{3}$, which is $1803 \mathrm{~kg} / \mathrm{m}^{3}$ of $\mathrm{NH}_{4} \mathrm{H}_{2} \mathrm{PO}_{4}$-based SPEA.

The applicable particle size range of $\mathrm{NH}_{4} \mathrm{H}_{2} \mathrm{PO}_{4}$-based powder in viscous resistance area can be calculated by formula (2): $d_{s} \leq 65 \mu \mathrm{m}$. The majority of $\mathrm{NH}_{4} \mathrm{H}_{2} \mathrm{PO}_{4}$-based powder particle sizes are less than 30 microns, so can be determined in the viscous resistance area. The calculation formula of the suspension speed of viscous resistance area is shown in formula (3).

$$
v_{0}=\frac{\left(\rho_{s}-\rho\right) g}{18 \mu} * d_{s}^{2}
$$

Where, $v_{0}$ stands for free suspension velocities, $\mathrm{m} \cdot \mathrm{s}^{-1} ; \mathrm{g}$ stands for acceleration of gravity, $\mathrm{m} \cdot \mathrm{s}^{-2}$, which is 9.81 in here.

The suspension velocities for $\mathrm{NH}_{4} \mathrm{H}_{2} \mathrm{PO}_{4}$-based powder particles with different sizes were calculated according to the formula (3), and the results is shown in figure 5.

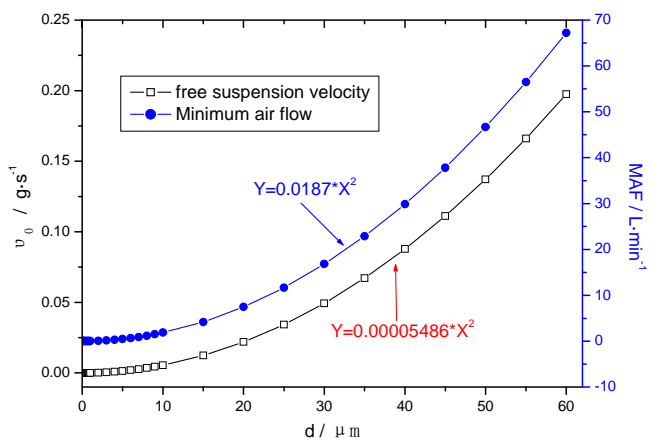

FIGURE V. SUSPENSION VELOCITIES FOR SUPERFINE NH4H2PO4 PARTICLES.

Figure 5 illustrates that the suspension velocity of $10 \mathrm{um}$, 20um and $30 u m$ particle is $0.0055 \mathrm{~m} / \mathrm{s}, 0.022 \mathrm{~m} / \mathrm{s}$ and $0.049 \mathrm{~m} / \mathrm{s}$, respectively. The internal diameter of cup-burner is $85 \mathrm{~mm}$, so airflow velocity is assure to be approximately above $17 \mathrm{~L} / \mathrm{min}$ $(0.05 \mathrm{~m} / \mathrm{s})$ as particle move upward during the experiment.

Considering the soft reunion and particle group effect of superfine powder, airflow velocity was chose to be $60 \mathrm{~L} / \mathrm{min}$ $(0.18 \mathrm{~m} / \mathrm{s})$ to make particle move at a certain speed and particle will move upward. The time is about $3 \mathrm{~s}$ when particle move from cup-burner powder entrance to the burning mouth. It will take $3 \mathrm{~s}$ at least when particle move to burning mouth after being discharging. Figure 6 shows the formation and fire extinguishing process of aerosols. As shown in Figure 6, after superfine powder is supplied for $3 \mathrm{~s}$, aerosols can be observed and begins interacting with flame, but the concentration of aerosols is too low to reach fire extinguishing concentration. When superfine powder is supplied for $5 \mathrm{~s}$, fire extinguishing concentration is achieved and fire was put out. Figure 6 illustrated that aerosols are homogenous in the cup-burner. In conclusion, the airflow velocity of $0.18 \mathrm{~m} / \mathrm{s}$ can assure that aerosols can be formed in cup-burner with the $\mathrm{NH}_{4} \mathrm{H}_{2} \mathrm{PO}_{4}$-based SPEA. 

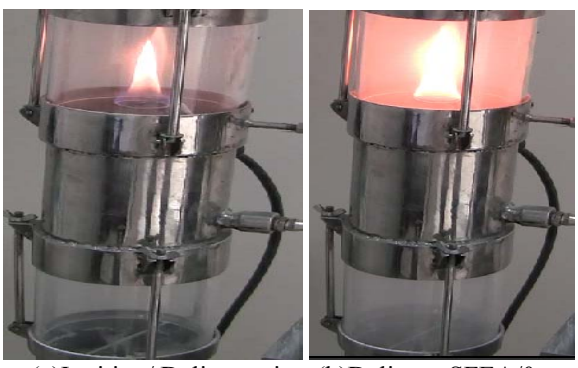

(a)Ignition/ Delivery air (b)Delivery SFEA/0s
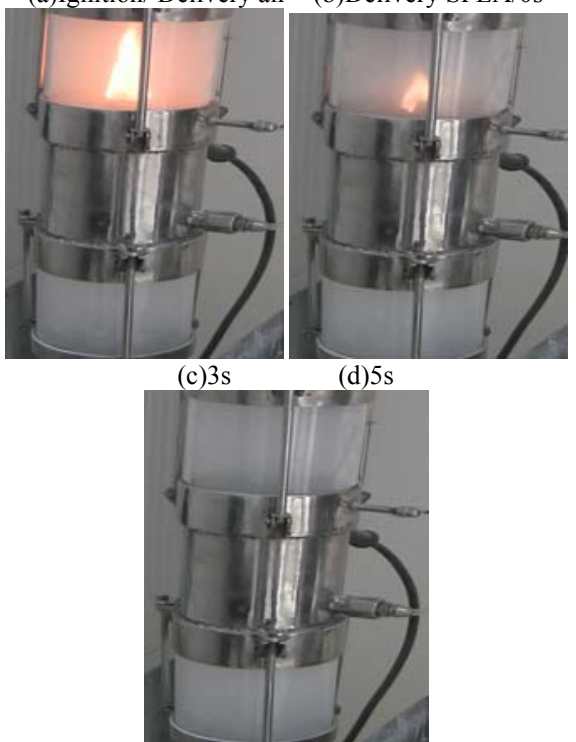

(e)flame extinguished

FIGURE VI. PROCESS OF SFEA AEROSOLS FORMATION AND FLAME SUPPRESSION.

\section{Fire Extinguishing Performance for NH4H2PO4-based SPEA}

Under the condition of that airflow velocity is $0.18 \mathrm{~m} / \mathrm{s}$, the extinguishing concentration and time on ethanol and n-heptane fuel with $\mathrm{NH}_{4} \mathrm{H}_{2} \mathrm{PO}_{4}$-based SPEA were determined, as shown in Table1.

TABLE I. EXPERIMENTAL RESULTS OF MEC WITH DIFFERENT FUELS.

\begin{tabular}{|l|l|l|l|}
\hline Fuel & $\begin{array}{l}\text { Air flow } \\
\text { rate } \\
\text { Lmin }^{-1}\end{array}$ & $\begin{array}{l}\text { Critical powder } \\
\text { delivery rate } \\
/ \mathrm{mg} \mathrm{s}^{-1}\end{array}$ & $\begin{array}{l}\text { Minimum extinguishing } \\
\text { concentrations } / \mathrm{gm}^{-3}\end{array}$ \\
\hline Ethanol & 60 & 79.8 & 79.8 \\
\hline n-heptane & 60 & 98.8 & 98.8 \\
\hline
\end{tabular}

Superfine powder moves upward under the carriage of airflow and then the mixture will interact with flame after getting into cup-burner. Superfine powder will spread into flame to extinguish fire. Although superfine powder has property similar to gas, diffusion of superfine powder is inferior. By contrast, the spreading time of superfine powder is longer. Especially, it will take much longer to achieve extinguishing concentration at the boot of flame. So, the powder concentration is referred to as fire extinguishing concentration after powder being injected into cup-burner for 30 s when the fire is extinguished.

The experimental results show that the minimum extinguishing concentration of $\mathrm{NH}_{4} \mathrm{H}_{2} \mathrm{PO}_{4}$-based SPEA on ethanol and $\mathrm{n}$-heptane fuel were $79.8 \mathrm{~g} / \mathrm{m}^{3}$ and $98.8 \mathrm{~g} / \mathrm{m}^{3}$, respectively. The minimum extinguishing concentration of $\mathrm{NH}_{4} \mathrm{H}_{2} \mathrm{PO}_{4}$-based SPEA is compared with other gaseous agents, as shown in Figure 7. It is found that the $\mathrm{NH}_{4} \mathrm{H}_{2} \mathrm{PO}_{4}$-based SPEA is a highly efficient fire-extinguishing agent, which is an average of $2 \sim 3$ times more effective than halon 1301, and an average of 5 8 times more effective than HFC-227ea.

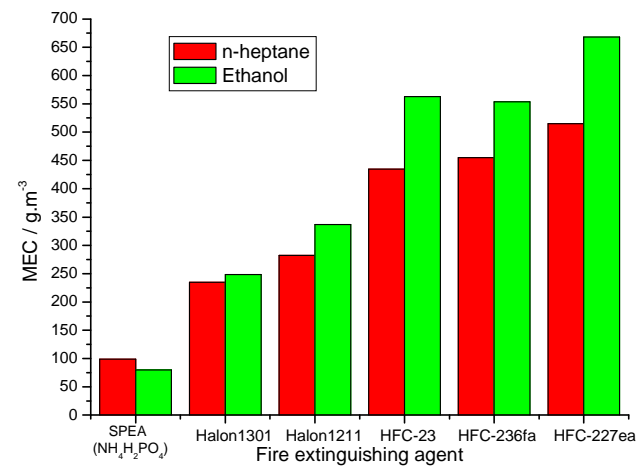

FIGURE VII. MINIMUM EXTINGUISHING CONCENTRATIONS OF DIFFERENT KINDS OF FIRE-EXTINGUISHING AGENTS.

It is indicated that the test methods based on the modified cup-burner apparatus can be used as a standard methods to evaluate suppression effectiveness and can provide a technique for comparing the performance of SPFE and gaseous agent. Also, it can provide a basis design parameters for the application of superfine powder fire extinguishing technology.

\section{CONCLUSIONS}

This study involved an experimental investigation on the fire extinguishing performance of $\mathrm{NH}_{4} \mathrm{H}_{2} \mathrm{PO}_{4}$-based SFEA in a modified cup burner apparatus, which was developed for testing the minimum extinguishing concentrations (MEC) of SFEA with different materials and particle sizes. Measurements were performed on flame burning both ethanol and n-heptane fuel using $\mathrm{NH}_{4} \mathrm{H}_{2} \mathrm{PO}_{4}$-based powder as the SFEA. For comparison, experiments results using halon 1301 and $\mathrm{CF}_{3} \mathrm{CHFCF}_{3}$ with the same test method were also reported. The main conclusions of this study included the following:

(1) The $\mathrm{NH}_{4} \mathrm{H}_{2} \mathrm{PO}_{4}$-based SPEA can be deliveried continuously and evenly in the range of $0.020 \mathrm{~g} / \mathrm{s}$ to $0.30 \mathrm{~g} / \mathrm{s}$ by the vibrating-spiral micro feeder of the modified cup-burner apparatus. Powder delivery rate was proportional to motor speed.

(2) According to the suspension-grade-model (SGD), those particles of the $\mathrm{NH}_{4} \mathrm{H}_{2} \mathrm{PO}_{4}$-based SPEA prepared in the experiment were in the viscous resistance area by theoretical calculation. In order to ensure that all particles were upward movement, a minimum air velocity of $0.05 \mathrm{~m} / \mathrm{s}$ was required. 
When the air flow reached $60 \mathrm{~L} / \mathrm{min}$, the $\mathrm{NH}_{4} \mathrm{H}_{2} \mathrm{PO}_{4}$-based SPEA aerosols can be formed uniformly in the cup burner.

(3) It is demonstrated that the $\mathrm{NH}_{4} \mathrm{H}_{2} \mathrm{PO}_{4}$-based SPEA is a highly efficient fire-extinguishing agent, which is an average of $2 \sim 3$ times more effective than halon 1301, and an average of 5 8 times more effective than HFC-227ea.

(4) The test method and apparatus based on cup-burner can be used as a standard method to evalute fire extinguishing performance of SFEA. The method can provide a basis design parameters for the application of superfine powder fire extinguishing technology. Therefore, this research is helpful for the engineering design of superfine powder fire extinguishing equipment, as well as has vital significance to the fire protection.

\section{ACKNOWLEDGEMENTS}

The author acknowledgment the support of this work by the National Key Technology Research and Development Program (Project No. 2014BAK17B02), the National Natural Science Foundation of China (Grant Nos. 51176078), and the Application \& Innovation Project of the MPS (Project No. 2012YYCXTJXF149)

\section{REFERENCES}

[1] Kranyansky M. Remote extinguishing of large fires with powder aerosols [J]. Fire and Materials,2006,30(5):371 -382.

[2] Zhou Xiaomeng, Jiang Lizhen, Chen Tao. Surface characteristics and fire extinguishing ability of superfine powder fire extinguishing agent[J].Journal of Combustion Science and Technology, 2009, 15(3):214-218.

[3] Du Lanping, Xie Delong, Dong Jingfei. Study on the Halon Alternative Technology[J]. Fire Science and Technonlogy, 2002,21(1):59-62.

[4] A. Hamins. Flame suppression effectiveness[R].NIST861,1994.

[5] Mikhail K. Studies of fundamental physical-chemical mechanisms and processes of flame extinguishing by powder aerosols [J]. Fire and Materials,2008,32(1) :27 -47.

[6] Hirst R. Measurement of flame-extinguishing concentration [J]. Fire technology, 1977(13):296-310

[7] A. Hamins. Flame extinction by sodium bicarbonate powder in a cup burner. Symposium (International) on Combustion, 1998,27(2):2857-2864

[8] Xu Dayong, Dai Xiaoying, Hua Min. Numerical simulation of superfine powder extinguishing agent movement released in non-fire room[J]. Journal of Nanjing University of Technology, 2012,(6):130-135.

[9] Lu Zijian, Cao Wenzhong, Liu Jin. Research of Suspension of Particle in Reactor[J]. Chemical Engineering, 1997, 25(5):42-46. 